\title{
¿Quiénes son los malos? Propaganda, kalokagathia y caricatura en los tebeos de la Guerra Civil a través de un ejemplo: Un miliciano rojo
}

\author{
Noelia Fernández García \\ Universidad de Oviedo \\ noelia.fdez.garcia@gmail.com
}

\begin{abstract}
RESUMEN: Durante el transcurso de la Guerra Civil, así como durante la posguerra española, la propaganda se convirtió en uno de los elementos políticos esenciales; y el arte, principalmente la arquitectura, la escultura y la pintura, cumplió esa función desde un primer momento. Sin embargo, los más pequeños tampoco fueron ajenos al adoctrinamiento, conseguido mediante la propaganda en los tebeos. El caso de Un miliciano rojo resulta ejemplar dentro de este campo, pues muestra cómo el bando nacional, finalmente vencedor en la contienda, se sirvió de un recurso tan antiguo como la kalokagathia para infundir el miedo hacia modelos considerados erróneos en la perseguida y futura nueva sociedad.
\end{abstract}

PALABRAS CLAVE: Guerra Civil, Tebeos, Propaganda, Kalokagathia, Adoctrinamiento infantil, Caricatura española.

\section{Who are the Evil Ones? Propaganda, Kalokagathia and Caricature in Comics during the Spanish Civil War through an Example: Un miliciano rojo}

\begin{abstract}
During the Spanish Civil War, as well as during the post-war period, propaganda turned into one of the essential political elements, and art - mainly architecture, sculpture and painting, accomplished that purpose from the very first moment. Even children were part of this indoctrination which was achieved by means of propaganda in comics. A great example of this is the comic titled Un miliciano rojo (A red militiaman), which perfectly shows how the eventually winners used the ancient idea of kalokagathia to instill a sense of fear towards the considered wrong models in the persecuted and future new society.
\end{abstract}

KEY WORDS: Spanish Civil War, Comics, Propaganda, Kalokagathia, Children's Indoctrination, Spanish Caricature.

Recibido: 14 de abril de 2015 / Aceptado: 14 de octubre de 2015.

Decía Peter Burke en su obra Visto y no visto que «las imágenes tienen por objeto comunicar. En otro sentido, en cambio, no nos dicen nada. Las imágenes son irremediablemente mudas» ${ }^{1}$. Siguiendo esta afirmación sobre la finalidad de las imágenes, en todos sus campos de actuación, a continuación reflexionaremos sobre su uso en momentos clave de la historia reciente, tal y como sucedió durante la Guerra Civil que asoló España desde 1936 a 1939, y nos centraremos en la utilización de las imágenes dirigidas al público infantil, a través de la historieta Un miliciano rojo.

Dentro de este ámbito, se han realizado varios estudios, destacando en los últimos tiempos la exposición Los Tebeos de la Guerra Civil Española. Niños y Propaganda, patrocinada por el Ministerio de Cultura, gracias al Centro Documental de la Memoria Histórica, y con la colaboración del Ayuntamiento de Salamanca y de la Fundación Salamanca Ciudad de Cultura, en el año 2008. Esta muestra ofreció un elenco de las revistas y tebeos dirigidos a los niños y publicados en los tres

FERNÁNDEZ GARCÍA, Noelia: «¿Quiénes son los malos? Propaganda, kalokagathia y caricatura en los tebeos de la Guerra Civil a través de un ejemplo: Un miliciano rojo", Boletín de Arte, n. ${ }^{\circ}$ 36, Departamento de Historia del Arte, Universidad de Málaga, 2015, pp. 85-91, ISSN: 0211-8483. 
años de la Guerra Civil, dentro del que se incluía la historieta que se analizará posteriormente. No obstante, si bien el enfoque histórico en su estudio nos ofrece una visión muy concreta de la época, el análisis artístico de estos tebeos, por su parte, también resulta importante pues nos aporta más argumentos de los ya conocidos, para apoyar las ideas que tenemos a día de hoy sobre cómo fueron utilizados los recursos estéticos y artísticos dentro del campo de la propaganda política durante la guerra, e incluso la posguerra, al igual que sucedió, por ejemplo, con el cartelismo, mucho más estudiado.

\section{El tebeo en España y su uso durante la guerra}

El origen de los cómics se sitúa en Europa y América a finales del siglo XIX, presentando peculiaridades propias, correspondientes a su aspecto formal y lingüístico, que dependían del panorama sociocultural y político en que surgiesen².

En el caso europeo, los orígenes de esta forma de comunicación podemos encontrarlos en la obra del suizo Rodolphe Töpffer quien, en 1837, hablando de su obra manifestó: «Cada dibujo de los que componen esta obra va acompañado de una o dos líneas de texto. Los dibujos sin este texto, tienen un significado oscuro; el texto, sin los dibujos, no significa nada. El total forma una especie de novela [...]»3.

En el caso de España, las primeras historietas fueron realizadas en los años posteriores al período revolucionario de septiembre de 1868, momento en que los creadores buscaban nuevas formas de comunicación por medio de la imagen. Así, llegaron a crear y utilizar los cómics, para los cuales toman como base el humor político, la tradición de la estampería y el auge de la novela por entregas ${ }^{4}$, muy presentes ya en el país.

Por otro lado, el origen etimológico del tebeo, entendido como compendio de historietas dirigido a un público infantil, es posterior ya que parece encontrarse en la España del siglo $X X$, concretamente, en la revista infantil TBO, creada en Barcelona en el año 1917, en la imprenta de Arturo Suárez.

Este tipo de historieta tiene de especial, como mencionamos anteriormente, el público al que va dirigida: los niños. Por ello, sus elementos básicos son la imagen y el texto, aunque este último con menor presencia para restar así complejidad a la historia narrada, motivo por el que suele ser simple y mostrar un mensaje corto y conciso. Por otro lado, la imagen, aunque suele depender de la época y autor, es el elemento artístico que tampoco resulta complejo para llegar mejor su público.

Los tebeos, especialmente los realizados durante el período bélico o el franquismo, reflejan la realidad social de una época y un país, así como desarrollan el sentido crítico frente a diversas situaciones ${ }^{5}$, por lo tanto no podemos pensar que los contenidos de los mismos están descontextualizados y desconectados de la realidad en que se producen, motivo por el que estas historietas fueron utilizadas para educar y enviar mensajes concretos a sus destinatarios finales. Por esta razón, tanto durante la guerra como en la posguerra española, con la gran polarización política, comenzó un enorme despliegue propagandístico por parte de los dos bandos enfrentados, el republicano que se sirvió más de la prensa el cartel, y el franquista, que utilizó en mayor medida las revistas, los diarios, los folletos y los tebeos ${ }^{6}$.

La respuesta más clara a "ipor qué el uso de los tebeos como propaganda?» se encuentra en los intentos de adoctrinamiento ideológico y encuadramiento paramilitar ${ }^{7}$ que sufrieron los más pequeños primero durante la guerra, para así ser captados con mayor facilidad, y durante la posguerra para asegurar una mayor fidelidad al régimen, pues no podemos obviar que, en caso contrario, «[...] el niño, dulce, manso, marginado de las maldades de la existencia y los odios y rencores de los votantes, es apolítico y escapa de los resentimientos ideológicos de sus mayores» ${ }^{8}$. Durante la guerra, las ideas fascistas eliminaron cualquier perspectiva pedagógica manifestada en los tebeos en los años previos y la lectura de los mismos, generalmente placentera y sin fines inmediatos ${ }^{9}$, fue instrumentalizada.

\section{Los tebeos durante la guerra, Valentí Castanys y su obra}

La reconcepción de las historietas como instrumentos de propaganda en el conflicto bélico, que asoló España durante tres años, dio lugar a numerosos tebeos realizados tanto en el bando republicano como en el denominado nacional. En un principio, se pensó que la guerra iba a durar poco tiempo, motivo por el que la actividad editorial continuó en distintos lugares de España que no tenían un frente abierto ${ }^{10}$; sin em- 
bargo cuando, en 1937, parecía que la duración del conflicto se iba a prolongar, la politización de los tebeos publicados por ambos bandos se hizo más que palpable.

Tanto en los cómics como en los tebeos publicados por la República, las diferencias de prioridades entre los que querían ganar la guerra y los que preferían la revolución ${ }^{11}$, o entre socialistas y anarquistas ${ }^{12}$, eran más que latentes, lo que supuso poca homogeneidad en la idea a transmitir a los lectores. Sin embargo, el bando nacional se dedicó a transmitir unas constantes ideológicas homogéneas ${ }^{13}$, no permitiendo la presencia de la enemistad entre falangistas y tradicionalistas en sus publicaciones ${ }^{14}$.

Por su parte, el bando republicano no solo publicaba tebeos plenamente propagandísticos, como Pionero Rojo, que pretendían adoctrinar al público más joven enviándoles mensajes sobre la importancia del trabajo y el desprecio que se debía mostrar hacia la riqueza ${ }^{15}$, sino que también contaban con publicaciones satíricas y humorísticas en las que ridiculizaban a Franco al igual que a sus generales, tal y como sucedió en Héroes del Sur, donde Franco era representado como un títere de Hitler y Mussolini ${ }^{16}$.

Sin embargo, no sucedía lo mismo con las historietas del bando alzado. Además de propugnar unas constantes ideológicas concretas, las historietas de los sublevados mostraban consignas adoctrinadoras también constantes. Así, la Falange Española contaba con un programa y líneas de actuación bien definidos que se correspondían con planteamientos propagandísticos enfocados a la captación de simpatizantes. Producto de esto nos encontramos con la revista Flecha, publicación de gran importancia en Aragón ${ }^{17}$ (que no debe ser confundida con Flechas, creada en San Sebastián). Por su parte, los tradicionalistas también tenían su publicación de cabecera, la revista Pelayos; esta apareció en diciembre de 1936 y fue editada por la Junta Nacional Carlista de Guerra, siendo su propósito principal el mismo que el de Flecha, búsqueda de simpatizantes carlistas infantiles, los cuales eran también identificados como «pelayos» 18 .

Los niños, identificándose con los protagonistas de su material de lectura, empezaron a reproducir todas las características que la literatura que consumían afirmaba que ellos poseían, tomando como natural las ideas que de ella emanaban ${ }^{19}$, y prolongaron así el enfrentamiento ideológico que había llevado a sus mayores a luchar en la guerra.

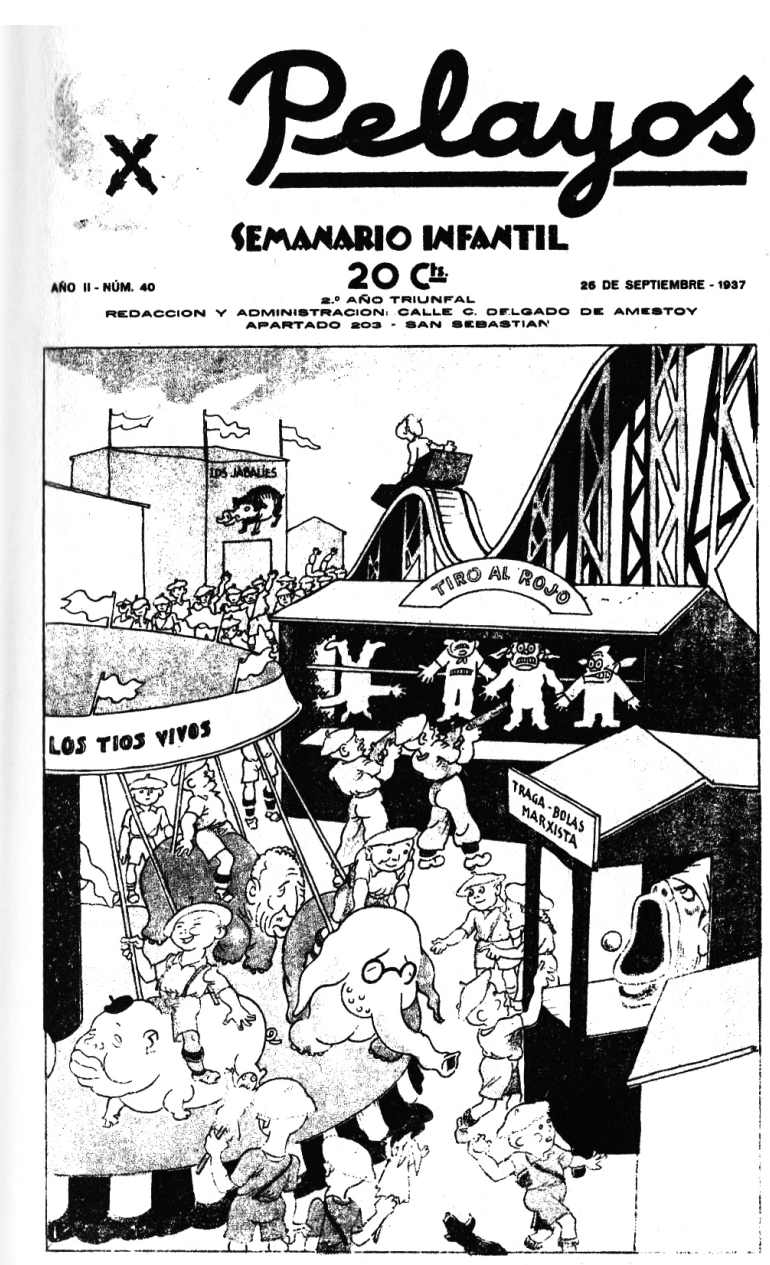

1. Portada de Valentí Castanys para Pelayos (Fuente: MARTín, Antonio, Historia del cómic español..., p. 175)

Valentí Castanys, autor de la historieta que nos centra en el presente artículo y que desarrollaremos posteriormente, ya desempeñaba su actividad en la industria durante los tiempos de la República. Se mudó a San Sebastián, dejando atrás Cataluña, cuando el 13 de septiembre de 1936 la ciudad fue conquistada por los carlistas del general Mola ${ }^{20} \mathrm{y}$ en enero de 1937 comenzó a participar en La Ametralladora, revista fundada por Tono y Mihura, autores enmarcados entre los humoristas denominados «del 27» que se alinearon bajo el régimen de Franco ${ }^{21}$.

Posteriormente también comenzó a participar en la revista Pelayos, antes ya mencionada, en la que demostró ser uno de los dibujantes más profesionales por contar con un estilo gráfico que demostraba claramente su dominio 

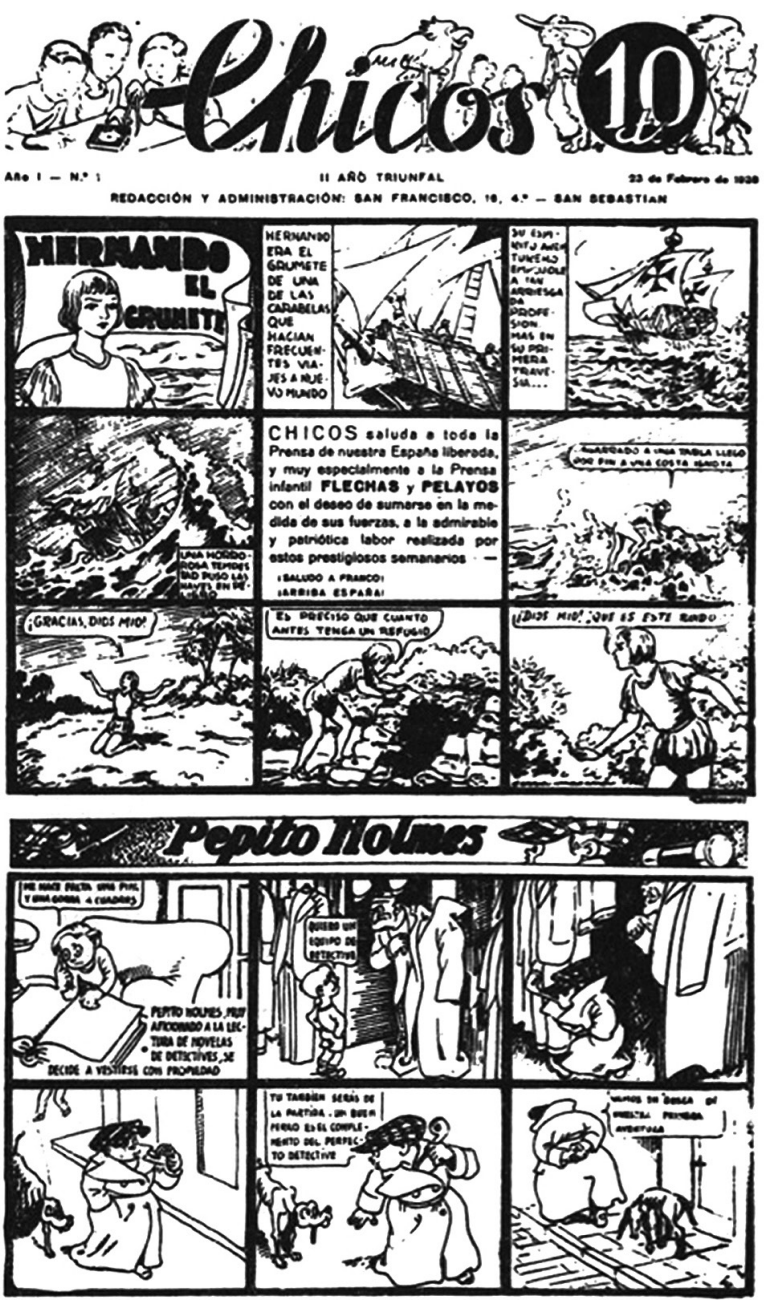

2. «Pepito Holmes» en la revista Chicos (Fuente: MARTín, Antonio, Historia del cómic español..., p. 212)

del lenguaje junto a una elaboración artística de gran funcionalidad $^{22}$. Además, es en las historietas y portadas diseñadas para Pelayos [1] donde podemos observar cómo el autor ponía de manifiesto un maniqueísmo personal que convertía su obra en un arma con una gran capacidad de propaganda al servicio del bando alzado ${ }^{23}$, debido a la repetición constante de estereotipos y consignas ideológicas que hacían que los lectores infantiles las absorbiesen de una forma totalmente eficaz, motivo por el que es tremendamente comprensible la afirmación: «[...] la virulencia de los ataques es aún mayor en los tebeos del bando rebelde. Sus publicaciones impresas sobre todo en San Sebastián
[...] son, si cabe, aún más despiadadas y rechazables» ${ }^{24}$. Castanys siguió trabajando para Flechas y Pelayos, después de la fusión de ambas revistas, siendo esta dirigida por Mosén Rosell y el Canónigo Vilaseca ${ }^{25}$, ambos huidos de la Barcelona republicana.

Posteriormente, dibujó para la revista Chicos, cuyo origen era también el San Sebastián ya conquistado ${ }^{26}$, manteniendo la firma de As, que había utilizado desde tiempos de la República ${ }^{27}$, y resultó uno de los autores clave junto a Mercedes Climona y Carmen Parras, aunque en este caso dejó el carácter panfletario más presente en Pelayos y se centró en el dibujo de historietas en una línea más de acción y aventuras como «Pepito Holmes» [2].

\section{Un miliciano rojo 28}

La historieta Un miliciano rojo fue publicada por la revista Pelayos en su número 25 del día 13 de junio de 1937 [3].

Los milicianos eran voluntarios armados no pertenecientes al ejército regular y, en gran medida, durante la guerra fueron uno de los apoyos más importantes con que contaba el bando republicano y suponían una de las oposiciones más férreas frente al bando alzado. Por este motivo, eran figuras muy perseguidas en los lugares conquistados por los nacionales, hecho que les obligaba a dedicarse a los robos como forma de subsistencia.

Este hecho fue aprovechado en este tebeo para sentar las bases de las características del personaje protagonista. Desde la España nacional, se pretendía mostrar a este arquetipo, del bando republicano y de izquierdas, como una mala persona, es decir, un monstruo de baja moralidad que pretendía hacer daño al prójimo con sus acciones. Esta demonización en el terreno de la moral consigue ser plasmada también en el aspecto físico del personaje a través de la kalokagathia y la caricatura. En primer lugar, la kalokagathia responde al modelo de creación en el que las cosas consideradas buenas presentan un aspecto físico «bello", mientras que lo considerado malo, representa, de forma indiscutible, la fealdad y la monstruosidad; por otro lado, en cuanto a la caricatura, la forma de representar de Castanys, con su personal maniqueísmo al que hicimos mención anteriormente, conecta con el concepto de caricatura en España al que Baudelaire hizo mención: «Los españoles es- 
tán muy dotados para lo cómico. Llegan rápidamente a lo cruel, y sus fantasías más grotescas contienen a menudo algo de sombrío»29, pues mostrar así al adversario, en este caso ideológico, ya se hacía en las caricaturas del siglo XIX y principios del $X X$.

El miliciano aparece representado como un personaje grotesco, con rasgos monstruosos como la mandíbula prominente, grandes incisivos, orejas puntiagudas, etc., remitiendo a figuras demoníacas y eliminando así cualquier rastro de humanidad. Así, Castanys pretendía representar a todos los republicanos como milicianos, a todos los milicianos como rojos y a todos los rojos feos, sucios y crueles ${ }^{30}$. Sin embargo, no solo la imagen del protagonista muestra el cariz inhumano del personaje, sino que también la concepción estética del título muestra esta idea, pues las letras aparecen bañadas en sangre, de forma que Castanys transmite la idea de un personaje profundamente sanguinario.

Como se ha señalado anteriormente, no solo la imagen es importante en los tebeos, a pesar de ser su elemento más esencial, principalmente cuando se dirige a un público infantil, sino también el texto. La yuxtaposición de ambos elementos en la primera viñeta de la historieta no puede evidenciar mejor la finalidad de adoctrinamiento e implantación de prejuicios, reafirmándonos en la idea del mensaje a comunicar, pues aparece en primer plano el miliciano monstruoso con un bocadillo en el que afirma rotundamente sus intenciones: "Tengo sed de robar y asesinar. Por algo soy rojo» [3]. El resto de las viñetas muestran al miliciano como un ser malvado capaz de asesinar a sangre fría a personas inocentes solamente con la intención de realizar sus fechorías. No obstante, como en casi todas las historias narrativas realizadas para niños, encontramos una moraleja final, pues, al final, el perro de la casa consigue salir de su jaula, después de que el miliciano intente hacerle daño golpeándolo con una piedra, y muerde al protagonista castigándolo por sus malas acciones.

El uso propagandístico de los tebeos viene marcado por la idea de coaccionar mentalmente a los más pequeños, adoctrinándolos a través de estas historietas, pues:

La psicología de las masas consideró que la propaganda, o el sistema de coacción mental para inculcar a los otros ideas y que crean que son ideas propias, no se debe basar en la formulación lógica de tales ideas, puesto que cada cual con-
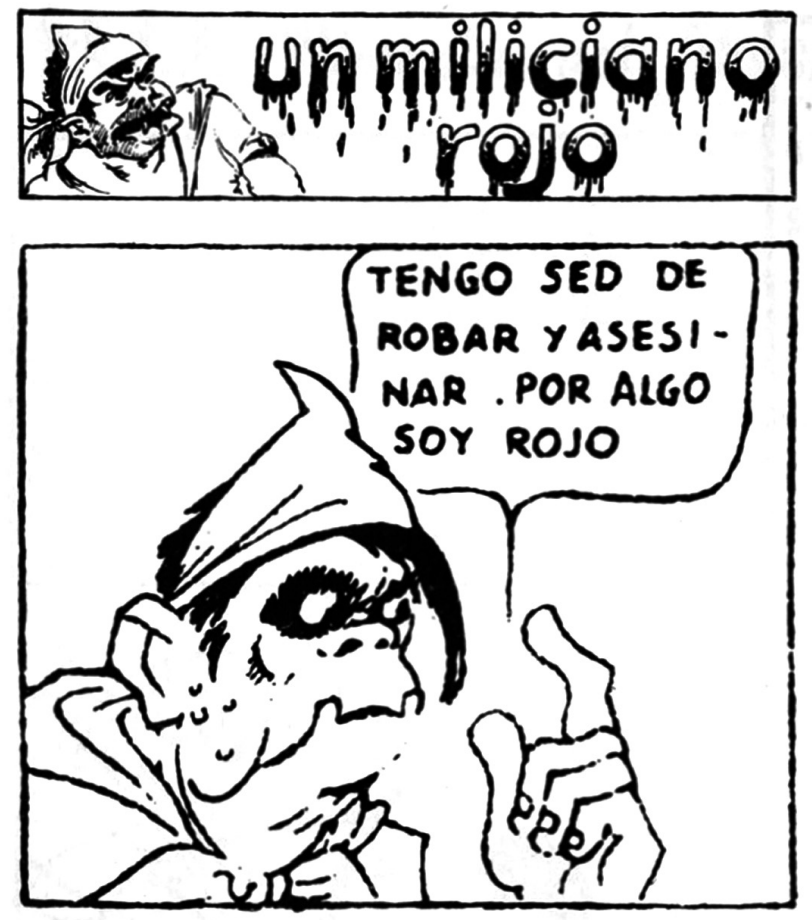

3. Título y primera viñeta de Un miliciano rojo (Fuente: MARTíN, Antonio, Historia del cómic español..., p. 174)

tra un concepto puede oponer otro en una discusión crítica, y puede rechazar el que se le ofrece. Lo eficaz es hacer vivir a los otros cualquier tipo de experiencia ${ }^{31}$.

Así, los niños viven la experiencia a través del tebeo y tras su lectura se les inculca la maldad presente en los opositores al alzamiento, en este caso, a través del arquetipo del miliciano, pues «la experiencia del lector con respecto a la obra que consume tiene su base y su eco en la experiencia de los personajes con su propia realidad»32. No obstante, en el caso de los tebeos el mensaje visual resulta más comprensible para el público infantil, hecho que justifica, más que sobradamente, los recursos de la kalokagathia y la caricatura, pues infundir el temor y el rechazo en niños resulta mucho más sencillo a través de la imagen.

Y es esta idea la que enlaza con el hecho de que, como se ha dicho anteriormente, los tebeos no están descontextualizados de la situación en que se desarrollaron, sino que son una manifestación del clima, en este caso totalmente bélico 
en que fueron creados, pues como manifestó Antonio Martín en su discurso inaugural de la exposición antes mencionada:

Los tebeos de la guerra civil española expresaban y comunicaban el clima de guerra a la sociedad civil a través de los niños lectores, muchas veces como agentes activos de la guerra de papel de la propaganda, mostrando las consignas, arquetipos políticos, campañas de opinión [...], y sobre todo el lavado de cerebro que para muchos niños supuso el adoctrinamiento al que se les sometía. ${ }^{33}$

Un miliciano rojo es un ejemplo clave para entender cómo la ideología y el pensamiento nacional se extendieron a través de esta forma propaganda desde los lugares que habían sido conquistados, como San Sebastián, en el País Vasco. Este tebeo, destinado aparentemente a los momentos de ocio de los más jóvenes, muestra cómo se pretendía que fuesen vistos los contrarios a lo que sería el futuro régimen, intentando evitar así que los más jóvenes reprodujesen un modelo social que se manifestaba como un elemento políticamente erróneo.

Así mismo, tras el final de la contienda se siguió con los planteamientos establecidos durante el conflicto civil, y en la década de los cuarenta, se seguía intentando encuadrar a la juventud, desde su infancia, para equipar al Estado con nuevas generaciones totalmente educadas por é ${ }^{34}$, motivo por el que se siguieron utilizando este tipo de publicaciones propagandísticas infantiles.

\section{Conclusiones}

En sustancia, podemos decir que el tebeo se nos presenta como un medio de comunicación e información, dirigido al público infantil, apoyado en un lenguaje que se basa en la experiencia visual y verbal, aunque en menor medida.

Un miliciano rojo, publicado en la revista tradicionalista Pelayos, es un ejemplo claro de la polarización política que vivió España durante la Guerra Civil, así como del uso propagandístico de los tebeos para la transmisión de mensajes por parte del bando nacional durante el período bélico. Además, esta historieta es uno de los ejemplos de cómo se sentó el precedente de lo que ocurriría durante la posguerra.

Asimismo, Un miliciano rojo muestra también las constantes ideológicas homogéneas que pretendía extender el bando nacional, siendo el profundo maniqueísmo de Valentí Castanys y su genial forma de representación, su arma principal en las revistas publicadas en San Sebastián, consideradas ya en la época como algunas de las más violentas, en tanto en cuanto su ataques gráficos eran más claros y despiadados.

Además, también podemos observar cómo, a través del recurso de la kalokagathia y la caricatura, se pretendía que el público más joven viese a los opositores al alzamiento como enemigos de la estabilidad social, monstruos de aspecto demoníaco y feroz que eran capaces de robar y asesinar, adalides de la violencia, que eventualmente recibirían su castigo.

\section{Notas}

1 BURKE, Peter, Visto y no visto, Barcelona, Crítica, 2005, p. 43

2 MARTín, Antonio, Historia del cómic español: 1875-1939. Barcelona, Gustavo Gili, 1978, p. 11

3 lbid., p. 14.

4 Ibid., pp. 11-12.

5 ARTACHO OLIHUERA, Concepción María, «¿Deben estar los cómics en las bibliotecas?», Boletín de Asociación de Bibliotecarios, n. 69, 2002 , p. 59.

6 MARTín, Antonio, «Los tebeos de la guerra civil española. Niños y propaganda», Tebeosfera 2. época, http://www.tebeosfera.com/documentos/textos/ los_tebeos_de_la_guerra_civil_espanola_ninos_y_propaganda.html (Fecha de consulta: 15-03-2015).

7 Ibidem.

8 DORFMANN, Ariel y MATTELART, Armand, Para leer al Pato Donald, México D.F., Siglo XXI, 2000, p. 23.

9 MERLO, Juan Carlos, «Lo que leen los niños. Historietas, tiras cómicas y tebeos», Educación y biblioteca, n. 34, 2003, p. 20.

10 BARRERO, Manuel, "Viñetas republicanas en la Guerra Civil Española». Tebeosfera 2. ${ }^{a}$ época http://www.tebeosfera.com/documentos/textos/vinetas_republicanas_en_la_guerra_civil_espanola.html

11 MARTíN, Historia del cómic español..., p. 156.

12 BARRERO, «Viñetas republicanas...».

13 MARTíN, Historia del cómic español..., p. 156

14 BARRERO, «Viñetas republicanas...».

15 Ibidem. 
16 Ibidem.

17 MARTíN, Historia del cómic español..., p. 166.

18 Ibidem.

19 DORFMANN y MATTELART, Para leer..., p. 26.

20 MARTíN, Historia del cómic español..., p. 166.

21 BARRERO, «Viñetas republicanas....".

22 MARTíN, Historia del cómic español..., p.175.

23 Ibidem.

24 BARRERO, «Viñetas republicanas...».

25 MARTín, Antonio, "La historieta española de 1900 a 1951», ARBOR Ciencia, Pensamiento y Cultura, n. 187,2011, p. 91.

$26 \mathrm{CIRICl}$, Alexandre, La estética del franquismo, Barcelona, Gustavo Gili, 1977, pp. 160-161.

27 BARRERO, «Viñetas republicanas...».

28 Para poder consultar este tebeo, así como otros ejemplos de la Guerra Civil, véase: http://www.mecd.gob.es/cultura-mecd/dms/mecd/cultura-mecd/ areas-cultura/principal/novedades/archivos/2008/los-tebeos-de-la-guerra-civil-espanola/Tebeos_Guerra_Civil_Ejemplares.pdf

29 BAUDELAIRE, Charles, Lo cómico y la caricatura, Madrid, Visor, 1989, p. 40

30 MARTín, Historia del cómic español..., p. 175

$31 \mathrm{CIRICl}$, La estética del franquismo..., p. 24.

32 DORFMANN y MATTELART, Para leer..., p. 30.

33 MARTíN, «Los tebeos de la guerra civil...".

$34 \mathrm{CIRICl}$, La estética del franquismo..., p. 158 
